\title{
CONCEPÇÃO INDESEJADA (WRONGFUL CONCEPTION), NASCIMENTO INDESEJADO (WRONGFUL BIRTH) E VIDA INDESEJADA (WRONGFUL LIFE): POSSIBILIDADE DA REPARAÇÃO NA PERSPECTIVA DO DIREITO CIVIL- CONSTITUCIONAL BRASILEIRO
}

\author{
WRONGFUL CONCEPTION, WRONGFUL BIRTH AND WRONGFUL LIFE: \\ POSSIBILITY OF RECEPTION IN PERSPECTIVE OF THE BRAZILIAN CIVIL \\ CONSTITUCIONAL LAW
}

\author{
${ }^{1}$ Eduardo Felipe Nardelli \\ ${ }^{2}$ Priscilla Zeni de Sá
}

\section{RESUMO}

A partir da perspectiva civil-constitucional, no ordenamento jurídico complexo e unitário, importa analisar se as situações de wrongful conception, wrongful birth e wrongful life podem ser tuteladas na realidade brasileira. Considerando a desnecessidade de uma regra positivada para cada fato jurídico é possível identificar no sistema jurídico amparo, constitucional e principiológico, para identificar a responsabilidade civil do médico nos casos citados. Pela aplicação da causalidade adequada deve-se identificar exatamente quais os danos indenizáveis, considerando também a possibilidade de reparação pela perda de uma chance.

Palavras-chave: nascimento, concepção ou vida indesejados; responsabilidade civil; perda de uma chance.

\begin{abstract}
From a civil-constitutional perspective, in a complex and unitary legal system, it is relevant to investigate if the wrongful conception, wrongful birth and wrongful life situations deserve legal protection in Brazil. Considering there is no need of a written law for every legal fact, it is possible to identify constitutional and principles support in the legal system, in order to recognize doctor's civil liability in the stated situations. By using the adequate cause theory, should be precisely identified which are the compensable damages, also considering a possible loss of a chance liability.
\end{abstract}

Keywords: wrongful birth, conception and life; civil liability; loss of a chance

\footnotetext{
1Especialista em Direito Civil Empresarial pela Pontifícia Universidade Católica do Paraná (PUCPR), Curitiba, Paraná, Brasil. Bacharel em Direito pela Universidade Regional de Blumenau (FURB/SC), Blumenau, Santa Catarina, Brasil. Advogado. Email: eduardo.fnl@gmail.com

2Mestre pela Pontifícia Universidade Católica do Paraná (PUCPR), Curitiba, Paraná, Brasil. Doutora pela Universidade do Vale do Rio dos Sinos (UNISINOS), São Leopoldo, Rio Grande do Sul, Brasil. Professora das especializações de Direito pela Pontifícia Universidade Católica do Paraná (PUCPR), Curitiba, Paraná, Brasil. Email: priscilazenidesa@icloud.com
} 


\section{INTRODUÇÃO}

A crescente inovação tecnológica na área da medicina possibilita, de certa forma, o diagnóstico cada vez mais precoce de deficiências físicas e/ou mentais de crianças em gestação. Por exemplo, existem, principalmente nos países desenvolvidos, técnicas diagnósticas de baixo custo, não invasivas e não colocando a vida do feto em risco, que podem detectar malformações ou anomalias do feto já nos primeiros meses de gestação.

Por outro lado, a ampla comercialização do atendimento médico-hospitalar, em que a saúde é vista, em geral, como a prestação de um serviço de consumo, reflete no grande número de demandas judiciais questionando diagnósticos, tratamentos e procedimentos técnicos adotados pelos profissionais da saúde, exigindo-se do médico um acerto nas condutas adotadas.

Além disso, deve-se ter em mente o direito dos pais e do nascituro à informação, consistente na obrigação que tem o médico de informar ao paciente todas as precauções essenciais ao seu estado de saúde, bem como adverti-lo sobre os possíveis riscos na escolha de um determinado tratamento ou intervenção e, em específico, o direito à saber de uma possível deficiência da criança. Além, é claro, de todos os outros deveres anexos inerentes a esse tipo de relação jurídica.

Tendo em vista, ainda, que um diagnóstico precoce se mostra de fundamental importância não apenas para o tratamento da deficiência, mas para a preparação financeiroeconômica e psicológica dos pais e familiares, ajudando na inserção da criança no meio familiar e social, já que são direitos do próprio nascituro deficiente a dignidade da pessoa humana e os valores básicos da igualdade de tratamento e oportunidade, justiça social, do respeito à dignidade da pessoa humana, do bem-estar.

Nesse contexto, é pertinente investigar os limites da responsabilidade do médico que não realiza um diagnóstico correto e, mais ainda, daquele que viola os deveres de informação, cuidado e consentimento informado, subtraindo aos genitores informações sobre uma possível deficiência da criança.

Chega-se, portanto, à problemática do presente artigo: Os fatos jurídicos denominados como concepção indesejada (wrongful conception), nascimento indesejado (wrongful birth) e vida indesejada (wrongful life), trazidos por estudos de direito comparado, encontram amparo no ordenamento jurídico brasileiro e são passíveis de gerar responsabilidade civil? 
O objetivo da pesquisa é encontrar no ordenamento jurídico brasileiro, complexo e unitário, os fundamentos para a caracterização da responsabilidade civil nos casos de concepção indesejada (wrongful conception), nascimento indesejado (wrongful birth) e vida indesejada (wrongful life), analisando as peculiaridades e variáveis que cada situação singularmente pode apresentar.

De início, serão tecidas algumas considerações sobre a constitucionalização do direito civil e de que modo e por que essa mudança de paradigma deve permear a análise dos pressupostos da responsabilidade civil, identificando as regras e princípios num ordenamento complexo e unitário.

Adentrando mais no tema, serão conceituados os pontos de partida da responsabilidade civil médica e suas peculiaridades, um breve escorço sobre a origem e atualidade do tema de estudo e, em seguida, as situações de concepção indesejada (wrongful conception), nascimento indesejado (wrongful birth) e vida indesejada (wrongful life) serão analisadas individualmente. Ao final, será dado um maior destaque à análise do nexo casual, sobretudo à aplicação da perda de uma chance nesses casos específicos, e à quantificação da reparação.

Este artigo baseia-se no método dedutivo de abordagem e tem o objetivo de analisar se estão presentes os pressupostos da responsabilidade civil nas situações delimitadas, empregando como técnica de pesquisa a documentação indireta (documental e bibliográfica).

\section{O DIREITO CIVIL CONSTITUCIONALIZADO}

A principiologia axiológica constitucional e a mudança do foco das relações jurídicas do patrimônio para a pessoa humana, frutos da Constituição Federal de 1988, redirecionaram sob vários aspectos fundamentais a produção do direito no Brasil. Assim, para se falar em novas categorias jurídicas ou, ainda, em novos bens merecedores de tutela e novas teorias para configuração e quantificação de danos há que se compreender primeiro, e necessariamente, o fenômeno da constitucionalização do direito civil. (FACHIN, 2003, p. 4).

As últimas constituições democráticas abdicaram, de certa forma, das recomendações programáticas e passaram a se estruturar em orientações para a produção da legislação ordinária ou infraconstitucional, tornando-se constituições principiológicas e, assim, relativizaram os principais elementos estruturantes dos códigos: os princípios (internos) e as normas gerais. (GONÇALVES NETO, 2001, p. 15). 


\section{Segundo Barroso (2006):}

[...] é bem de ver que todos os principais ramos do direito infraconstitucional tiveram aspectos seus, de maior ou menor relevância, tratados na Constituição.

[...]

Embora o fenômeno da constitucionalização do Direito, como aqui analisado, não se confunda com a presença de normas de direito infraconstitucional na Constituição, há um natural espaço de superposição entre os dois temas. Com efeito, na medida em que princípios e regras específicos de uma disciplina ascendem à Constituição, sua interação com as demais normas daquele subsistema muda de qualidade e passa a ter um caráter subordinante. Trata-se da constitucionalização das fontes do Direito naquela matéria. Tal circunstância, nem sempre desejável, interfere com os limites de atuação do legislador ordinário e com a leitura constitucional a ser empreendida pelo Judiciário em relação ao tema que foi constitucionalizado.

Tal se deu, segundo Fachin (2015, p. 8-9), em uma atuação constitutiva de três faces, quais sejam, formal, através de regras positivadas tanto na Constituição, quanto o próprio direito constitucional, bem como na legislação infraconstitucional, submetida à supremacia da Constituição; substancial, isto é, pela normatividade dos princípios constitucionais, a exemplo, a eficácia horizontal dos direitos fundamentais; e prospectiva, uma dimensão propositiva e transformadora da atividade produtiva do direito, uma visão do direito como instrumento de transformação social. A partir dessa perspectiva, os códigos e outras leis esparsas, deixam de ser lidos sob uma ótima produtivista e passam a ser analisados sob outra ótica, de cariz constitucional, na qual a reprodução do direito civil encontra limites nos direitos fundamentais da pessoa humana. (PERLINGIERI, 2002, p. 4). Daí afirmar que que tanto os princípios e regras são considerados como normas (GUASTINI, 2009, p. 42), e por isso componentes do sistema, unitário. (LOBO, 2014). Tepedino acrescenta ainda a dignidade da pessoa humana, a igualdade substancial e o valor social da livre iniciativa, que ao lado da justiça social e da solidariedade aventadas por Lobo, se mostram como valores consagrados pela Constituição. (TEPEDINO, 2002).

Todavia, essa mudança de perspectiva não é meramente formal e não se traduz somente na leitura conjunta de todo ordenamento, composto por princípios e regras, mas especialmente nas inter-relações entre direito civil e direito constitucional; passa, também, pela compreensão por parte do civilista de que os direitos fundamentais são tanto um limite como uma possibilidade de sua atuação hermenêutica, derrubando aquela ideia de direito civil como um sistema fechado e lhe permitindo um diálogo intertextual próprio da doutrina constitucional. (FACHIN, 2015, p. 8). 
Daí, abrem-se novos horizontes do cenário atual do direito civil: além da incidência direta das regras constitucionais nas relações privadas, tem-se, ainda, tensões entre a principiologia constitucional e as normas codificadas; atuação estatal em relações entre particulares, dando eficácia às garantias fundamentais e reinterpretação dos códigos à luz das constituições contemporâneas; superação da lógica do "tudo ou nada" e possibilidade de redução da eficácia de uma norma sem afetação da validade dos institutos civis. (DWORKIN, 2002; FACHIN, 2015, p. 10-11; 182).

Essa abertura, como destaca Tepedino (2002, p. 2), impõe a obrigação, sobretudo ao intérprete, de que toda legislação infraconstitucional seja lida de acordo com a "tábua axiológica" da Constituição, que ganha expressiva relevância na interpretação das cláusulas gerais.

Além dessa interpretação axiológica, as cláusulas gerais podem comportar-se diversamente de acordo com as funções normativas da técnica dogmática (estabilização, progresso, descarga, técnica, controle e heurística), possibilitando a concreção de direitos fundamentais no âmbito das relações privadas, viabilizando compreensão de cada conceito fundamental à luz do caso concreto. (CACHAPUZ, 2014, p. 57; 66). Essas balizas hermenêuticas impedem que as cláusulas gerais, principalmente aquelas que remetem a princípios e direitos fundamentais, sejam “[...] tratadas como um espelho, no qual todos enxergam o que desejam ver." (SARLET, 2015, p. 478).

É o caso, por exemplo, dos artigos 186 e 927 do Código Civil brasileiro (BRASIL. Lei $\left.\mathrm{n}^{\circ} 10.406,2002\right)$, que positivam uma cláusula geral de responsabilidade, possibilitando um conceito amplo e abstrato de dano indenizável, a ser definido pelo intérprete no caso concreto, a partir da principiologia constitucional.

Mas essa ampliação de horizontes só é possível partindo do pressuposto de que o ordenamento jurídico é um sistema unitário e hierarquicamente disposto; isto é, um conjunto de princípios e regras com fim último de ordenar a coexistência dos indivíduos. Isso porque não se pode ignorar que as leis, códigos, estatutos e outros diplomas legais expressam, cada qual, ideologias e visões de mundo diferentes daquelas que fundamentam a sociedade atual, assim como daquelas de propiciaram a promulgação da Constituição Federal de 1988. Logo, a solução para cada caso concreto deve ser buscada no ordenamento como um todo e, sobretudo, na principiologia constitucional. (PERLINGIERI, 2002, p. 2; 5).

Isso não significa, entretanto, que não possa haver pluralidade e heterogeneidade de fontes para o direito; até porque não se trata de uma questão simplesmente topográfica, mas 
sim de correta determinação dos problemas. Em outras palavras, ao invés de se enquadrar um problema em um diploma legal, deve-se, partindo das peculiaridades do caso, encontrar as normas aplicáveis, quais sejam suas fontes. (PERLINGIERI, 2002, p. 6-8).

Assim, é possível estender a tutela estatal a direitos violados não disciplinados ou reconhecidos expressamente na legislação civil, mas possíveis a partir da leitura constitucional, ou mesmo de outras leis que não tenham como temática central a regulamentação civil, o que confirma a tese da unidade do ordenamento, baseada na hierarquia constitucional, de Perlingieri (2002, p. 55).

Nesse contexto, acompanhado pela evolução, principalmente tecnológica da sociedade, é possível falar em novos direitos ou, em outras palavras, em tutela jurídica de danos que antes eram suportados exclusivamente pela vítima. De um lado, pela erosão dos pressupostos clássicos da responsabilidade civil (SCHREIBER, 2012) e, de outro, pela ampliação de suas definições.

\section{WRONGFUL CONCEPTION, WRONGFUL BIRTH E WRONGFUL LIFE}

Os termos wrongful conception, wrongful birth e wrongful life são espécies de ações indenizatórias que têm por fundamento uma falha médica que resulta em uma concepção, gravidez ou nascimento indesejado. Essas denominações surgiram, inicialmente, nos Estados Unidos da América, porém, diante das particularidades jurídicas desse país - principalmente a grande autonomia dos estados-membros em competência legislativa -, não há, como adverte Peteffi da Silva (2010. Destaques no original), unanimidade na nomenclatura desses institutos:

Alguns autores, como Michael Murtaugh, utilizam-se do termo wrongful birth para denominar todo e qualquer tipo de ação movida por pais de filhos indesejados, podendo estes nascer sadios ou com alguma deficiência grave. Por outro lado, Darpana Sheth representa outra tendência doutrinária, que acredita que a designação wrongful birth deve ser empregada apenas para os casos de pais que deram à luz crianças deficientes.

$[\ldots]$

Kathleen Mahoney, em aprofundado artigo sobre a nomenclatura utilizada pela jurisprudência norte-americana, reafirma a falta de consenso reinante na área, mas concorda com a tendência majoritária de considerar que o wrongful conception normalmente envolve gravidez não planejada, falhas contraceptivas por parte dos médicos e o posterior nascimento de uma criança "saudável", enquanto o wrongful birth normalmente envolve gravidez planejada, falha médica no período pré-natal, falha em testes genéticos e o posterior nascimento de uma criança deficiente. 
O primeiro caso que invocou a concepção de um ser humano como dano, segundo Peteffi da Silva (2012), ocorreu em 1934 nos EUA, no estado de Minnesota. Nessa ação, mesmo após a realização de uma vasectomia, recomendada pelos médicos em razão dos riscos que uma gravidez traria à esposa, o casal concebeu uma criança. É de se notar que - apesar do alerta dos médicos - a gestação transcorreu sem complicações e criança nasceu saudável. Todavia, os pais resolveram ingressar em juízo pedindo reparação pela concepção indesejada. Apesar dos argumentos dos autores, a Suprema Corte de Minnesota entendeu que o bem jurídico tutelado era a incolumidade da mãe, em razão da gravidez de risco, e como esta transcorreu normalmente, não havia dano a ser indenizado, julgando improcedentes os pedidos.

A expressão wrongful life, por sua vez, só foi empregada 1963, em um tribunal do estado de Illinois, e teve como diferencial o fato de ser usada em contraposição às chamadas ações por morte indevida (wrongful death), generalizando-se, assim, para indicar qualquer ação em que a vida fosse invocada como dano. (SIMÕES, 2010).

Merece destaque, também, o notório caso Perruche. Nele, a Corte de Cassação francesa, órgão competente para dizer a correta aplicação e interpretação da lei francesa, acolheu o pedido de reparação de danos postulado por um adolescente em razão de uma grave deficiência física causada pela rubéola durante a gravidez de sua mãe; muito embora ela tivesse declarado de forma expressa a vontade de realizar o aborto se tal doença fosse diagnosticada. (SCHREIBER, 2012, p. 96).

A Corte reconheceu, inclusive, a independência e, portanto, a possibilidade de cumulação, da reparação dos danos sofridos pela própria criança e daqueles sofridos por seus pais. (GODOY, 2007). A propósito, esse caso culminou com a edição de uma lei que proibiu de forma expressa ações que tivessem por fundamento o simples nascimento indesejado, causando ainda hoje intenso debate entre os juristas franceses. (SCHREIBER, 2012, p. 96).

A par das origens heterogêneas dos institutos e, por consequência, de suas diferentes denotações, os trabalhos em língua portuguesa parecem estabelecer algum consenso quanto à taxinomia dessas ações (PETEFFI DA SILVA, 2010; 2012; HOLANDA, 2012; SIMÕES, 2010). Assim, como o objetivo desse artigo é analisar se os pressupostos da responsabilidade civil estão presentes no conteúdo dessas ações, opta-se por empregar a nomenclatura utilizada por esses autores, alertando-se, no entanto, que esse consenso é basicamente unilateral.

Wrongful conception pode ser traduzido literalmente como concepção indesejada ou indevida e assinala, como o próprio nome deixa claro, ações que têm por fundamento uma 
falha médica - representada por defeitos em métodos contraceptivos, em cirurgias de esterilização, abortos entre outros -, que culmina com a gravidez que se tentou evitar. (PETEFFI DA SILVA, 2012).

O termo wrongful birth é usado para designar um tipo de ação fundamentada em um erro culposo do médico que resultou em um nascimento indesejado, em que os genitores da criança compõem a parte passiva e pedem a reparação em nome próprio. De forma semelhante, a ação denominada wrongful life parte do mesmo fato - isto é, uma falha culposa do médico que resultou em um nascimento indesejado -, mas apresenta a própria criança, representada pelos pais, como autora da ação. (HOLANDA, 2012).

Essas ações, até por sua origem (EUA e França, principalmente), têm mais relevância em ordenamentos jurídicos que permitem o aborto indiscriminadamente - o que não é o caso do Brasil. Contudo, tais ações podem ter importância no Brasil, por exemplo, nos casos de esterilização malsucedida, anticoncepcionais defeituosos e diagnósticos equivocados de anencefalia (ADPF $n^{\circ} 54$ ) ou de paternidade advinda de estupro, já que o aborto é permitido em certos casos.

Nesse sentido, Peteffi da Silva (2012) também percebeu a possibilidade de importação desses institutos:

[...] notou-se que as espécies de responsabilidade civil estudadas poderiam ter causa em procedimentos contraceptivos permitidos e muito usados no Brasil, como a laqueadura tubária (comumente conhecida como ligadura de trompas) e a vasectomia. Mesmo sob essa nova perspectiva, ainda observase que as hipóteses clássicas de wrongful birth, por estarem vinculadas a gestações planejadas (que acabaram frustrando a "estratégia procriativa" dos pais), ainda mantém uma dependência muito grande do direito ao abortamento voluntário encontrado em outros países.

Diante dessas premissas, e em um contexto de comercialização do atendimento médico-hospitalar, prestação de um serviço típica de uma relação de consumo, refletindo em um grande número de demandas judiciais questionando diagnósticos, tratamentos e procedimentos técnicos adotados pelos profissionais da saúde, abre-se espaço para possibilidade de que os prejuízos advindos de um nascimento indesejado - tido muitas vezes como algo sagrado e, consequentemente, impossível de causar efetivamente um dano - seja tutelado pelo direito.

Ainda mais se considerada a tutela constitucional ao direito dos pais, bem como do nascituro, à informação, consistente na obrigação que tem o médico de informar ao paciente todas as precauções essenciais ao seu estado de saúde, bem como adverti-los sobre os 
possíveis riscos na escolha de um determinado tratamento ou intervenção. E, em específico, o direito à saber de uma possível deficiência da criança.

Nessa mesma linha de pensamento, um diagnóstico precoce se mostra de fundamental importância não apenas para o tratamento da deficiência, se possível, mas para a preparação financeira, econômica e psicológica dos pais e familiares, ajudando na inserção da criança no meio familiar e social - o que pode, também, ser reconhecido como um direito.

Apesar de essa discussão não ser tão recente - o primeiro caso ocorreu na década de 30 do Século XX - as questões que dela exsurgem são bastante atuais e as respostas parecem longe de um consenso.

\section{POSSIBILIDADE DE REPARAÇÃO DOS DANOS ADVINDOS DE "WRONGFUL CONCEPTION", "WRONGFUL BIRTH" E "WRONGFUL LIFE" NA PERSPECTIVA DO DIREITO CIVIL CONSTITUCIONAL BRASILEIRO}

A configuração da responsabilidade civil médica exige uma conduta voluntária, um prejuízo injusto e nexo de causalidade entre os dois. Não se pode olvidar, também, que a responsabilidade do médico é, em regra, subjetiva, isto é, necessita da prova da culpa em sentido estrito (em qualquer de suas três formas: imperícia, negligência ou imprudência). (KFOURI NETO, 2010, p. 81).

Desse modo, os pressupostos da responsabilidade civil médica em nada diferem daqueles atribuídos à responsabilidade civil de uma forma geral. Há, todavia, uma peculiaridade na responsabilidade médica que é o agente. Segundo Croce e Croce Júnior (2002, p. 13, grifos dos autores):

\footnotetext{
Evidentemente, só pode ser o médico responsivo, que se acha compos suae mentis na plena posse de suas faculdades mentais, portanto em grau de prever as consequências das próprias ações, visto que, se for o dano produzido por indivíduo desprovido de habilitação técnica ou de habilitação legal, além da responsabilidade civil responderá, no foro criminal, pelo delito de curandeirismo (CP, art. 284) ou de exercício ilegal da Medicina (CP, art. 282).
}

No panorama do sistema jurídico unitário conforme elucidado no item anterior a questão deve ser analisada pelo prisma dos princípios constitucionais, da regras civis sobre a responsabilidade, sem olvidar da aplicação do Código de Defesa do Consumidor (BRASIL. Lei $\left.n^{\circ} 8.078,1990\right)$ quando verificada uma relação de consumo. Por força do artigo $14, \S 4^{\circ}$, do CDC, a responsabilidade médica, quando prestado o serviço pelo profissional liberal, é 
subjetiva, ou seja, necessita da prova da culpa, que não pode ser presumida pelo mero insucesso do diagnóstico ou do tratamento. É imprescindível que se demonstre que o insucesso adveio da negligência, imprudência, imperícia ou dolo do médico. (CAVALIERI FILHO, 2012, p. 404).

Além desses pressupostos, a relação entre médico e paciente é permeada por deveres éticos, que estabelecem padrões objetivos de conduta desse profissional. Dias (2006, p. 337) divisa cinco deveres (obrigações implícitas) impostos ao médico na relação com o paciente e seus familiares: dever de conselho; dever de cuidados; obtenção do consentimento; abstenção de abuso ou desvio de poder e dever de sigilo.

O dever de conselho ou de informação é a obrigação que tem o médico de informar ao paciente todas as precauções essenciais ao seu estado de saúde, bem como adverti-lo sobre os possíveis riscos na escolha de um determinado tratamento ou intervenção. Deve-se, no entanto, ter em mente que o paciente normalmente não tem conhecimento técnico específico para compreender todas as instruções médicas e, a depender de seu estado psicológico, nem sempre é aconselhável prestar-lhe informações sobre probabilidade de óbito, complicações etc. (DIAS, 2006, p. 337; PEREIRA, 2002, p. 150).

Próximo ao dever de conselho está o dever de obtenção do consentimento. O médico necessita informar o paciente (ou seus familiares) dos procedimentos adotados, dos riscos etc. e precisa que o doente consinta com seus métodos. Dias (2006, p. 340-341) observa que nem todo procedimento adotado deve ter o consentimento do paciente. Apesar de todo procedimento médico apresentar riscos (inerentes à natureza da atividade médica), o consentimento prévio do paciente (ou de seus familiares, caso ele esteja impossibilitado) só será necessário em casos que ofereçam um perigo real, ou seja, um risco acima da média, quando existam contraindicações ao procedimento adotado. Segundo Pereira (2002, p. 152), os procedimento cirúrgicos, em regra, não podem ser realizados sem o aval do enfermo ou de sua família.

Por óbvio, o consentimento do paciente não exime o médico da responsabilidade advinda de possíveis erros, aliás, o dever de obtenção do consentimento não pode ser entendido como um instrumento de "defesa" do médico por eventuais equívocos, mas como um meio de dignificação do paciente.

Além disso, é importante destacar que o consentimento não é um ato irrevogável e inalterável. (FRANÇA apud DIAS, 2006, p. 342). Com efeito, o médico está obrigado a aceitar a vontade do paciente ou de quem o represente e é importante documentar o 
consentimento do doente, comprovando a autorização do tratamento ou procedimento, isso porque:

O médico, desrespeitando a vontade do paciente, estará assumindo todos os riscos de produzir um resultado danoso, inclusive podendo sofrer sanções penais, pois lhe é vedado dispor livremente do corpo alheio (SCHAEFER, 2006, p. 78-79).

Outro dever implícito no contrato médico é o dever de cuidado. O profissional que abandonar seu cliente ou, não podendo atendê-lo, fazer-se substituir por outro profissional inabilitado, infringirá esse dever. Esse dever abrange não só o cuidado imediato, no momento da consulta, mas também a vigilância sobre o paciente - principalmente sobre os que apresentam problemas psicológicos, que por seu estado debilitado precisam de uma atenção especial do médico. Contudo, existem, naturalmente, situações em que, protegido pelo código de ética médica, o profissional pode se escusar de prestar assistência. (DIAS, 2006, p. 338$339)$.

Nenhuma pessoa está obrigada a se submeter a um determinado tratamento, "Em princípio, o médico não pode obrigar o seu cliente a submeter-se a um dado tratamento, uma vez que cada um é senhor de seu corpo, cabendo ao interessado autorizá-lo". (CARVALHO SANTOS apud PEREIRA, 2002, p. 152). Portanto, não pode o médico realizar experiências com o corpo do paciente. É nisso que consiste o dever de abstenção de abuso ou desvio de poder. É, assim como os outros deveres, uma garantia ao doente de que não será usado para o teste de procedimentos médicos não consolidados - e nesse caso nem o consentimento do paciente exime a responsabilidade do médico. (DIAS, 2006, p. 343).

O dever de sigilo é a proibição, dirigida ao médico e ao hospital, de divulgar informações obtidas do paciente ou apuradas durante o tratamento. Da mesma forma que os demais deveres, o dever de sigilo não é apenas uma restrição à autuação do médico e do hospital, mas um direito do paciente, estritamente ligado à sua dignidade. (DIAS, 2006, p. 346).

Como ensina Schaefer (2006, p. 102-103), a violação do dever de sigilo ofende o direito à intimidade do paciente (Constituição Federal, 1988, art. 5, X) e só pode ser quebrado em situações excepcionais pelo médico ou por autorização legal ou judicial.

Portanto, a violação a qualquer desses deveres caracteriza uma conduta culposa do médico e pode induzir sua responsabilização, desde que presentes os outros pressupostos dano e nexo de casualidade, vislumbrados esses requisitos contemporaneamente, 
vislumbrando-se a responsabilidade por danos. (FROTA, 2014).

\subsection{Wrongful conception}

Como dito, as ações de wrongful conception se fundamentam em um erro do médico que culmina com uma gravidez que se queria evitar, podendo ocorrer desde através de uma falha no procedimento abortivo a até a prescrição de métodos contraceptivos ineficazes. (PETEFFI DA SILVA, 2012).

Essa definição deixa claro que as ações de concepção indesejada se originam de uma conduta médica, cuja voluntariedade ou culpa depende das circunstâncias de cada caso. É possível, por exemplo, identificar negligência na conduta de um médico que prescreve anticoncepcionais sabidamente ineficazes e imperícia em um procedimento esterilizatório (vasectomia ou laqueadura) ou abortivo mal realizado.

A falha na atuação médica, em si, já é passível de configuração de um dano (PEREIRA, 2013). Entretanto, a discussão aqui é se a consequência dessa falha, a concepção não desejada, e todas as suas implicações - despesas médicas, surpresa e desconforto com a gravidez etc. - pode ser considerada um dano.

Se por um lado os direitos de personalidade e direitos fundamentais são irrenunciáveis e indisponíveis, consequência lógica do princípio da dignidade da pessoa humana - ou seja, como a vida é um direito fundamental, não seria possível considerá-la um dano -, por outro:

[A partir do momento em que] são oferecidos serviços de diagnóstico prénatal e a lei considera a interrupção da gravidez não punível em certos casos, a grávida tem direito ao funcionamento normal e eficaz desses serviços para obter as informações relevantes sobre o andamento da gestação, de tal modo que possa beneficiar do regime da interrupção voluntária da gravidez quando for caso disso. Mesmo antes do nascimento e da verificação de outros danos no feto, a grávida já sofreu uma diminuição do seu direito à autodeterminação informada - uma lesão provocada pela má prática do médico. (SIMÕ̃ES, 2012).

Como bem assinala Simões (2012), essa questão deve ser respondida de forma técnica, sem lançamento de argumentos metajurídicos (religiosos, morais etc.). Até porque, a própria Constituição internaliza no ordenamento regras e princípios de caráter ético, caso da reparação integral.

Nesse contexto, a concepção pode caracterizar um dano indenizável, a partir da 
violação culposa dos deveres de cuidado, informação entre outros, uma vez que o médico atinge a liberdade de autodeterminação da mãe e a liberdade de planejamento familiar das famílias. Com efeito, a violação dos deveres éticos e contratuais por parte do médico, ainda mais pelas peculiaridades dessa espécie de contrato, em que o paciente é dependente emocional e tecnicamente, gera um dano.

Quando se analisa a conduta e o dano, parece claro que não existe óbice à configuração do nexo causal. É certo que se não houvesse a intervenção do médico, o nascimento ocorreria de qualquer forma. A questão, todavia, é que ao assumir a responsabilidade pela paciente gestante e pelo nascituro, o médico também assume todos os deveres legais e éticos inerentes ao contrato e sua conduta antijurídica, omissiva ou comissiva, está diretamente ligada ao resultado danoso.

Todavia, há sempre que se ter em mente que os procedimentos cirúrgicos como esterilização e aborto sempre guardam certa margem de erro ou de recivida, sobre a qual o médico não tem controle absoluto. É de se destacar, nessa linha, que apesar da álea, sempre presente na ciência médica, é obrigação desse profissional informar corretamente seus pacientes e familiares.

Elucidativo, nesse ponto, o recente acórdão do Tribunal de Justiça do Estado de Santa Catarina (SANTA CATARINA. Tribunal de Justiça, 2015) no qual o tribunal enfrentou um caso de concepção indesejada, no qual a apelante alegou defeito do medicamento anticoncepcional, que não impediu a concepção.

Nada obstante a evidente relação de consumo e a inversão do ônus da prova; isto é, o dever de a empresa farmacêutica produzir a prova de inexistência de defeito do medicamento anticoncepcional, entendeu o relator do recurso de apelação que: “[...] qualquer anticoncepcional existente no mercado de consumo não possui eficácia absoluta, mesmo que os pacientes façam uso de forma adequada e seguindo orientações médicas."

Acresceu, ainda, que nesses casos específicos, existem causas externas que não podem ser mensuradas e/ou imputadas ao fornecedor do produto - expressamente alertadas pela bula do medicamento -, tais como a utilização errada do medicamento e a utilização conjunta de outros medicamentos, que podem interferir na eficácia do anticoncepcional. 


\subsection{Wrongful birth}

O "nascimento indesejado" ou wrongful birth ocorre quando, após a concepção, o médico subtrai ou negligencia aos genitores do nascituro alguma informação relevante que, caso eles tivessem conhecimento, faria com que interrompessem a gravidez. No Brasil, é possível citar os casos de feto com anencefalia, da gravidez de risco para a mãe e da gravidez advinda de estupro, hipóteses em que o ordenamento jurídico brasileiro permite o aborto. Em países que permitem o aborto indiscriminadamente, qualquer outra doença ou malformação do nascituro, pode configurar o nascimento indesejado.

É de se destacar, novamente, que não é o médico que causa tais doenças ou malformações, estas derivam de uma causa natural ou estranha à conduta médica, ele apenas não informa aos pais sobre sua existência - tolhendo-lhes a possibilidade de optar por um método abortivo. Nas palavras de Simões (2012,) “O médico não se apresenta responsável pela implantação da deficiência, que surge normalmente logo desde o início da vida pré-natal. No entanto, a omissão do esclarecimento sobre essa deficiência é tida como ilícita."

Essa ilicitude caracteriza-se pela violação ao direito ao resultado seguro na realização de exames, direito à informação e, novamente, direito à liberdade de autodeterminação e planejamento familiar. Esses direitos, logicamente, correspondem a obrigações assumidas pelo médico no contrato de prestação de serviços, sobretudo o de informar corretamente à mãe e à (futura) criança. (HOLANDA, 2012).

Essa violação ao direito de informação pode ocorrer de, pelo menos, três formas distintas: a) quando o médico não informa, ou informa insuficientemente, os pais da probabilidade de o nascituro vir com uma grave patogenia congênita; b) através de um diagnóstico pré-implantatório negligente, que é a escolha de um embrião não saudável para inseminação artificial; c) quando o médico não informa à mãe e ao pai de que o feto sofre de uma malformação grave. (SIMÕES, 2012).

Percebe-se, assim, que não existe nexo de causalidade entre a conduta culposa do médico e a patologia do recém-nascido. Porém, é possível estabelecer um liame entre a conduta culposa do médico e a perda da possibilidade (ou chance) de realizar um procedimento abortivo ocasionada pela negligência do dever de informação.

Para tanto, nem é preciso adentrar na discussão acerca de se o nascimento configuraria ou não um dano, porquanto o que foi subtraído da vítima foi a chance de interromper a gravidez, e como a chance pode ser considerada um dano autônomo, 
independente do resultado final, pode também ser integralmente reparada de acordo com a probabilidade que a vítima tinha de alcançar o resultado (probabilidade de êxito na interrupção da gravidez).

Assim, lançando mão da teoria da perda de uma chance, é possível a adoção das ações de wrongful birth, visando uma reparação retrospectiva da perda de uma probabilidade passada. Em outros termos, se a conduta culposa do médico - representada, principalmente, pela violação aos deveres de informação e consentimento informado - acaba com todas as probabilidades de o evento futuro ocorrer (possibilidade de aborto ou tratamento pré-natal), existe um dano indenizável (a chance perdida) e há nexo de causalidade. (HIGA, 2012, p. 176-177).

\subsection{Wrongful life}

As ações de wrongful birth e wrongful life são desdobramentos distintos que advém de um fato comum. Se naquela são os genitores que pleiteiam reparação pelo nascimento indesejado, nesta é a própria criança quem requer indenização. E a simples mudança ocorrida no polo ativo - mesmo que a ação tenha fundamento idêntico - muda completamente o ângulo pelo qual se analisa a questão.

Em tese, o nascimento com uma doença incurável causado por uma falha médica, seja diagnóstica ou laboratorial, afronta um direito a uma vida saudável ou ainda o direito a uma vida digna, consequência lógica do princípio da dignidade da pessoa humana. Todavia, a efetivação de um direito ao nascimento saudável, em caso de uma doença incurável, é o nãonascimento. Logo, ao se admitir a existência de um direito ao nascimento saudável, se reconhece um direito a não nascer, o que é, no mínimo, contraditório. (HOLANDA, 2012).

Para Holanda (2012), o nascituro, além de não ter um direito a não nascer, não é o destinatário dos deveres éticos e legais do profissional médico. Isso porque, a partir de uma leitura contratual da relação jurídica entre médico, paciente (genitores) e nascituro, ela classifica este último apenas como terceiro. Ou seja, o médico não teria um dever de informação ou de diagnóstico para com o nascituro, mas somente para com seus pais e, por isso, conclui pela possibilidade de aplicação da ação de wrongful birth e pela impossibilidade da ação de wrongful life.

Outra, no entanto, é a conclusão de Simões (2010). Partindo do pressuposto de que o ordenamento jurídico (no caso do autor, o ordenamento português, mas que pode ser trazido 
ao ordenamento brasileiro) não atribui à vida um valor absoluto - aliás, não atribui valor absoluto a nenhum direito fundamental - ele conclui que é possível relativizar o direito à vida na esfera da própria personalidade individual, deixando que seu titular disponha, em certos casos, desse direito.

Para ele, não é o nascimento, pura e simplesmente, e tampouco a existência de uma deficiência que configura o dano. É o nascimento deficiente, a conjunção de ambos, porquanto essa condição é que acarreta sofrimento e dificuldades para a vida do recémnascido. É o peso da existência nessas condições que se apresenta reparável. E, por fim, arremata: por qual razão seria possível conceder uma indenização aos pais da criança pelo nascimento indesejado e para a criança, que é quem efetivamente suportará a doença por toda a sua vida, a indenização deve ser negada? Trata-se, em sua visão, de uma manobra processual que não pode impedir a reparação de um dano causado injustamente.

Desses dois raciocínios, o primeiro parece mais correto. Na esteira do entendimento de Holanda (2012), não há como reconhecer um direito ao não nascimento. Primeiro, porque a titularidade de um direito pressupõe um sujeito capaz de exercê-lo; logo, a efetivação desse pretenso direito eliminaria o futuro sujeito. Segundo, não há como imputar ao médico, por inexistência de nexo causal, toda a responsabilidade pelo "peso da existência" da criança. A propósito, o direito brasileiro adota a teoria da causalidade adequada e, por isso, não é razoável concluir que todos os futuros infortúnios da vida da criança têm como causa idônea a falha médica durante a gestação.

Nesse contexto, diferentemente, nas ações de wrongful birth, não é possível a indenização pela perda da chance, pois o autor da ação, a criança, não tinha a possibilidade de interromper a gravidez - prerrogativa concedida somente a seus pais -, consequência lógica de não se reconhecer um direito subjetivo a não existir. Por outro lado, foi diretamente prejudicado pela supressa do nascimento com deficiência e pode pleitear a reparação moral e material daí decorrente.

4.4 Considerações sobre a perda de uma chance e sobre a quantificação da reparação

Sabe-se que para o ordenamento jurídico brasileiro, dentre todos os fatores sem os quais um determinado fato não ocorreria, consideram-se relevantes, ou causadores do dano, somente aquelas condutas que, no momento de sua prática, previsivelmente causariam o dano. Acresça-se a isso a definição do artigo 403 do Código Civil (BRASIL. Lei no 10.406), de que 
“as perdas e danos só incluem os prejuízos efetivos e os lucros cessantes por efeito dela direto e imediato", definindo a adoção da causalidade adequada.

As ações de concepção e nascimento indesejadas têm em comum a possibilidade de reparação da chance perdida. Nesses casos, os genitores da criança perdem a chance de interromper a concepção ou a gravidez. Trata-se, portanto, de um evento aleatório que segue o seu curso - e que poderia ter sido interrompido, caso não houvesse a falha do médico no diagnóstico ou na informação - e que se conhece o resultado final: a concepção ou o nascimento.

Desconsiderando eventuais indenizações decorrentes diretamente da falha de diagnóstico, da falta de prestação de informações claras, da violação aos deveres de cuidado e afronta ao direito de autodeterminação e livre planejamento familiar dos pais, não é possível estabelecer o nascimento ou a concepção como um dano decorrente da conduta médica. Eis porque o dano, nessa hipótese, é a perda da chance da interrupção do evento aleatório.

Pois bem, partindo desses pressupostos, é possível concluir pela responsabilização dos agentes (médico e instituição de saúde). Contudo, a reparação não pode ultrapassar a chance perdida, sob pena de afronta à teoria da causalidade adequada.

Em outros termos, a conduta culposa do médico não autoriza a conclusão de que é responsável por todos os gastos decorrentes da concepção ou nascimento indesejado. De fato, sua falha contribuiu para que isso ocorresse, mas se o dano, como dito, não está no nascimento ou na concepção, a ele só pode ser imputada a perda da chance de interrupção. Por esse mesmo motivo, quando se diz que não é responsável por todas as despesas futuras do filho indesejado, não se está afastando o princípio da reparação integral do dano, pois se esta indenizando integralmente a chance perdida.

A propósito, considerar, nesses casos, o erro médico como causador dos prejuízos materiais e morais decorrentes da alimentação, escolarização e sustento de uma forma geral da criança ad eternum é retornar à teoria da equivalência das condições atribuindo a um dano um número sem fim de causas, uma vez que sempre será possível regressar a um fato anterior e enquadrá-lo como causa de algo.

Com efeito, é perfeitamente possível a reparação da chance perdida nos casos de wrongful birth e wrongful conception, todavia, essa reparação não pode extrapolar o contorno do dano sofrido - que é chance perdida - e alcançar prejuízos futuros das vítimas que decorrem apenas indiretamente e de forma mediata da conduta culposa do profissional da medicina. 


\section{CONSIDERAÇÕES FINAIS}

O objetivo inicial deste trabalho foi investigar a possibilidade de recepção, pelo direito brasileiro, da reparação dos danosa advindos de wrongful conception, wrongful birth e wrongful life por meio da análise dos pressupostos da responsabilidade civil. A bibliografia sobre o tema não é unânime em relação à nomenclatura dessas ações, por isso foram adotadas as definições utilizadas em estudos publicados na língua portuguesa.

Inicialmente, foi abordada a mudança, substancial e formal, de perspectiva do direito civil especialmente a partir da Constituição de 1988. Essa mudança de paradigma fez com que a legislação, sobretudo a civil - historicamente fechada a influências externas - passasse a ser interpretada e reproduzida tendo como limite e condição de possibilidade os princípios e regras constitucionais e os direitos fundamentais da pessoa humana. Com efeito, deixando-se de lado a ótica produtivista, e a partir da principiologia constitucional, tudo isso entendido no sistema jurídico, complexo e unitário, é possível alagar que os conceitos clássicos de dano, nexo causal e conduta antijurídica e, consequentemente, admitir a tutela de "novos" direitos, possibilitando a reparação de danos não previstos expressamente na legislação positivada, falando-se contemporaneamente em responsabilidade por danos.

Foram descritos, de forma geral, os deveres médicos, principalmente os deveres de diagnóstico, informação e consentimento informado e de como a violação desses deveres pode acarretar a responsabilização desse profissional, que responde subjetivamente.

Por fim, foram analisados os pressupostos da responsabilidade civil em relação a cada um dos fatos analisados, chegando-se a seguinte conclusão: As ações que tem por fundamento uma falha médica que culmina com uma concepção indesejada (wrongful conception) ou um nascimento indesejado (wrongful birth) preenchem os requisitos da responsabilidade civil e permitem a reparação tanto de danos materiais e morais - pela falha de diagnóstico, pela infração dos deveres médicos, entre outros - quanto pela perda da chance de evitar ou interromper a gravidez. As ações de wrongful life, que compartilham o mesmo fundamento das ações de wrongful birth, mas têm no polo ativo a própria criança, também preenchem os requisitos da responsabilidade civil em relação à reparação material e moral, sobretudo pela surpresa do nascimento, do qual a criança é a maior prejudicada. Todavia, ao contrário das outras ações, não é possível a reparação da chance perdida nas ações de indenização por nascimento indesejado, porquanto a chance subtraída da criança é a de não 
nascer. Admitir tal reparação seria admitir um direito a não existência, um paradoxo jurídico, uma vez que o exercício desse direito pressupõe um sujeito de direito, que só pode existir após o nascimento com vida.

No entanto, não se pode esquecer que o direito brasileiro adota a teoria da causalidade adequada, o que implica dizer que, em tais ações, o erro médico não pode ser classificado como causador dos prejuízos materiais e morais decorrentes da alimentação, escolarização e sustento de uma forma geral da criança ad eternum. Essa interpretação remonta à teoria da equivalência das condições e atribuí um dano um número sem fim de causas, uma vez que sempre será possível regressar a um fato anterior e enquadrá-lo como causa de algo.

Assim, responde-se afirmativamente ao problema proposto na presente pesquisa, afirmando que os fatos jurídicos ora analisados, da concepção indesejada (wrongful conception), do nascimento indesejado (wrongful birth) e da vida indesejada (wrongful life) encontram amparo no ordenamento jurídico brasileiro e são passíveis de gerar responsabilidade civil, estando esta amparada não apenas em uma norma positivada, mas sim num complexo e unitário sistema jurídico, fundamentado não apenas de regras, mas também de princípios que orientam, norteiam e abrem a interpretação das normas.

\section{REFERÊNCIAS BIBLIOGRÁFICAS}

BARROSO, Luís Roberto. Neoconstitucionalismo e constitucionalização do direito: o triunfo tardio do direito constitucional no Brasil. Disponível em: http://www.luisrobertobarroso.com.br/wpcontent/themes/LRB/pdf/neoconstitucionalismo_e_constitucionalizacao_do_direito_pt.pdf. Acesso em: 21.08.2015.

BRASIL. Lei $\mathrm{n}^{\circ}$ 10.406, de 10 de janeiro de 2002. Institui o Código Civil. Disponível em: http://www.planalto.gov.br/ccivil_03/leis/2002/110406.htm. Acesso em: 02.08.2015.

BRASIL. Lei $\mathrm{n}^{\circ}$ 8.078, de 11 de setembro de 1990. Dispõe sobre a proteção do consumidor e dá outras providências. Disponível em: http://www.planalto.gov.br/ccivil_03/leis/18078.htm. Acesso em: 02.08.2015.

BRASIL. Tribunal de Justiça do Estado de Santa Catarina. Apelação cível no 2013.081066-9. Apelante: Ivonete dos Santos Brito de Andrade. Apelada: União Química Farmacêutica Nacional S/A. Relator: Desembargador Sebastião César Evangelista. Florianópolis, 27 de agosto de 2015. DJe $n^{\circ}$ 2184.

CACHAPUZ, Maria Cláudia Mércio. A construção de um conceito de privacidade, as cláusulas gerais e a concreção de direitos fundamentais. In: MARTINS-COSTA, Judith. Modelos de direito privado. São Paulo: Marcial Pons, 2014. 
CAVALIERI FILHO, Sergio. Programa de responsabilidade civil. 10. ed. rev. e ampl. São Paulo: Atlas, 2012. xxvi, $614 \mathrm{p}$.

CROCE, Delton; CROCE JUNIOR, Delton. Erro médico e o direito. 2. ed. São Paulo: Saraiva, 2002. xxii, $389 \mathrm{p}$.

DIAS, José de Aguiar; DIAS, Rui Berford. Da responsabilidade civil.11. ed. Rio de Janeiro: Renovar, 2006. 1148 p.

DWORKIN, Ronald. Levando os Direitos a sério. Trad. Nelson Boeira. São Paulo: Martins Fontes, 2002.

FACHIN, Luiz Edson. Comentários ao novo Código Civil: do direito de família, do direito pessoal, das relações de parentesco. Rio de Janeiro: Forense, 2003. vol. xviii.

FACHIN, Luiz Edson. Direito civil: sentidos, transformações e fim. Rio de Janeiro: Renovar, 2015. 226p.

FROTA, Pablo Malheiros da Cunha. Responsabilidade por danos: imputação e nexo de causalidade. Curitiba: Juruá, 2014.

GODOY, Gabriel Gualano de. ACÓRDÃO PERRUCHE E O DIREITO DE NÃO NASCER. Universidade Federal do Paraná, 2007. Disponível em: http://dspace.c3sl.ufpr.br/dspace/bitstream/handle/1884/12026/nao_nascer_FINAL.pdf;jsessionid=584 6962BF23BB6C28E60D9FE35E2B7F3? sequence=1. Acesso em: 29.07.2015.

GONÇALVES NETO, Alfredo de Assis. O projeto de Código Civil em si e em matéria societária. OAB Revista da Ordem dos Advogados do Brasil. Rio de Janeiro, a. 31, nº 73, jul/dez 2001.

GUASTINI, Riccardo. Os princípios constitucionais como fonte de perplexidade. In: TEIXEIRA, Anderson Vichinkeski (Org.); OLIVEIRA, E. S. de (Org.) . Correntes Contemporâneas do Pensamento Jurídico. 1. ed. São Paulo: Manole, 2009. P. 42

HOLANDA, Caroline Sátiro de. Violação à liberdade reprodutiva: uma análise dos pressupostos da responsabilidade civil para os casos de wrongful birth e wrongful life. In: XXI Congresso Nacional do Conpedi, 2012, Niteroi. XXI Congresso Nacional do CONPEDI. Florianópolis: FUNJAB, 2012. Disponível em: http://www.publicadireito.com.br/artigos/?cod=4e2a6330465c8ffc. Acesso em: 29.07.2015.

KFOURI NETO, Miguel. Responsabilidade civil do médico. 7. ed. rev., atual. e ampl. São Paulo: Editora Revista dos Tribunais, 2010.

LÔBO, Paulo. Metodologia do direito civil constitucional. In RUZYK, Carlos Eduardo Pianovisky. Eduardo Nunes de Souza, Joyceanne Bezerra de Menezes; Marcos Ehrhardt. (Org.). Direito civil constitucional. 1ed. Florianópolis: Conceito, 2014. P. 19-27 
MARTINS-COSTA, Judith. A boa-fé no direito privado: sistema e tópica no processo obrigacional. São Paulo: Ed. Revista dos Tribunais, 1999.

PEREIRA, Caio Mario da Silva. Responsabilidade civil. 9. ed. rev. Rio de Janeiro : Forense, 2002. 350p. Inclui índice.

PERLINGIERI, Pietro. Perfis do direito civil. Tradução de: Maria Cristina De Cicco. 3. ed., rev. e ampl. Rio de Janeiro: Renovar, 2002. 369p.

PETEFFI DA SILVA, Rafael. Responsabilidade civil pela perda de uma chance: uma análise do direito comparado e brasileiro. 3. ed. São Paulo: Atlas, 2013.

PETEFFI DA SILVA, Rafael. STERSI, Ricardo Soares. RESPONSABILIDADE CIVIL PELO NASCIMENTO DE FILHOS INDESEJADOS: COMPARAÇÃO JURÍDICA E RECENTES DESENVOLVIMENTOS JURISPRUDENCIAIS. Conpedi, 2012. Disponível em: http://www.publicadireito.com.br/artigos/?cod=a11ce019e96a4c60. Acesso em 29.07.2015.

PETEFFI DA SILVA, Rafael. Wrongful conception, wrongful birth e wrongful life: possibilidade de recepção de novas modalidades de danos pelo ordenamento brasileiro. Ajuris (Porto Alegre) (Cessou em 1998. Cont. ISSN 1679-1363 Revista da Ajuris), v. 117, p. 311-341, 2010. Versão digital disponível

em: http://www.ambitojuridico.com.br/site/?n_link=revista_artigos_leitura\&artigo_id=10781\&revista_cad erno=7. Acesso em: 02.08.2015.

SARLET, Ingo Wolfgang. A eficácia dos direitos fundamentais: uma teoria geral dos direitos fundamentais na perspectiva constitucional. 12. ed. rev. atual. e ampl. Porto Alegre: Livraria do Advogado Editora, 2015. 512p.

SCHAEFER, Fernanda. Responsabilidade civil do médico \& erro de diagnóstico: direito material e processual, convênios e resoluções, jurisprudência. Curitiba: Juruá, 2006. 232p.

SCHREIBER, Anderson. Novos paradigmas da responsabilidade civil: da erosão dos filtros da reparação à diluição dos danos. 4. ed. São Paulo: Atlas, 2012.

SIMÕES, Fernando Dias. Vida indevida? As acções por wrongful life e a dignidade da vida humana. Revista de Estudos Politécnicos, Polytechnical Studies Review. Vol. VIII, nº 13, 2010. Disponível em: http://www.academia.edu/362485/Vida_indevida_As_accoes_por_wrongful_life_e_a_dignidade_da_v ida_humana. Acesso em: 29.07.2015.

TEPEDINO, Gustavo. Crise de fontes normativas e técnica legislativa a parte geral do Código Civil de 2002. In TEPEDINO, Gstavo. [coord.]. A parte geral no novo Código Civil: estudos na perspectiva civil-constitucional. Rio de Janeiro: Renovar, 2002.

TEPEDINO, Gustavo. O direito civil-constitucional e suas perspectivas atuais. In: Temas de direito civil . - Tomo III Rio de Janeiro: Renovar, 2009. 